\title{
Review of Research on the Equalization of Basic Health Services
}

\author{
Yuan-Fang Liu ${ }^{1, a}$, Xi Guo ${ }^{1, b,}$, Juan $W^{1, c}$, Jian-Xin Xi ${ }^{1, d}$ \\ ${ }^{1}$ School of Public Management, Inner Mongolia University, Hohhot, P.R. China \\ a0477lyf@163.com, bguoxi@imu.edu.cn, ${ }^{c} 15226012831 @ 163 . c o m,{ }^{d} x i j i a n x i n 198954 @ 163 . c o m$
}

${ }^{*}$ Corresponding author

Keywords: Equalization of basic health services, Medical services, Public health.

\begin{abstract}
The equalization of basic health services (EBHS) is an important part in building a service-oriented government, and is essential to safeguarding citizens' health in maximum and ensuring the equality of citizens to enjoy their right on health fair. Review of researches on the EBHS is the first step of estimating the equalization levels of EBHS, and the main basis on a further enhancing of the basic health services quality and efficiency. Herein, this paper focused on the connotation and researching objects of the EBHS, concluded the content of current researches on the EBHS in different perspectives, given a theoretical basis to promoting the equality of citizens, equitable access to basic health services.
\end{abstract}

\section{Introduction}

The right of health is a basic right of citizens. The level of the equalization of basic health services (EBHS) directly affects the fair and equitable of residents to enjoying their basic health services. There are two key words of the EBHS, one is "basic health services" and the other is "the equalization". Scholars have agreed that the content of basic health services is in two parts, including public health and basic medical services. The EBHS is not a simple average of basic health services, but providing in accordance with the economic situation, equitable access to citizens, thus can be fairly shared in the process of obtaining. Basic health services and ultimately result the equalization, ultimately achieve the equalization of basic health services.

\section{Researches on the connotation of the EBHS}

Foreign researches focused on the emphasis of basic health services of equal opportunity over the connotation of the equalization of basic health services, each citizen owning the right of equal to enjoy basic health services. Chinese scholars define the connotation of EBHS on the perspective of "opportunity - process - result" and "citizen demand - supply of government".

\section{Foreign researches on the connotation of the EBHS}

In America, health care accessibility and health insurance is often synonym. One has insurance that will enjoy equally health services utilization in a certain extent [1]. In Canada, people have the right to enjoy the reasonable combination of basic health care. No person will be discriminated against the factors of income, age, health status [2].

Acheson D believes that health is not equal phenomenon which can be avoided. The main reasons are factors that changes outside of the medical services quality and the changes in wealth, lifestyle, genetic and environmental. And many other changes of factors beyond the control of health services [3]. Gopal Srddnivasan agree that a widely accepted reason that universal accessing to basic health services is equality of opportunity which can ensure the health of medical and health services. But from the social determinants of health based, equality of opportunity does not necessarily ensure universal access to basic health services [4].

\section{Chinese researches on the connotation of the EBHS}

The EBHS is not average, but relatively equal in area, such as urban, rural areas and groups. Chinese scholars define the connotation of the EBHS are mainly from the perspective of citizen 
demand and the angle of combining government supply. Scholars study citizen demand mainly from the thought of equal opportunity, progress and equal results, taken the three aspects into account to define the connotation of basic health services.

Perspective of "Opportunity - Process- Result". Scholars think that the EBHS mainly mean that citizens enjoy equal opportunity, results and process. Ying-Chun LAN thought the equalization should be reflected in three aspects: Firstly, the opportunities for residents to enjoy basic public services are equal, such as citizens have the right to the health; The second is that the results of citizen enjoy public services are equal; Thirdly is that during the process of providing the general the EBHS, respecting the right of freedom choice of members in society [5].

Xiu-Ze CHANG and Ying ZHANG believe that the equalization of basic health services is the opportunities for residents to enjoy basic public services in equal and results are generally equal, and during the process of services, respecting the right of freedom choice of members in society [6-7].

Zhuang-Cai FU has proposed the equalization of basic medical services refers to all citizens enjoying equal opportunity of basic medical services, and much the same results. What's more, the gap between basic medical services is controlled in a social tolerance range [8].

Perspective of "Citizen Demand - Government Supply". Some scholars define the connotation of the EBHS from both demand of citizen and supply of government. Qiong-Lian LIU proposed the equalization of basic public health services are "the bottom line" of basic health services, and we should implement according to the conditions of supply and demand to improve the satisfaction of all members in society over basic health services, and improve national health. She proposed the values and operating standards of the equalization of basic services [9].

Hong ZHAO et al proposed more comprehensive connotation of the EBHS. They think the EBHS is in the range of government's public finances affordable, scientific coordination and integration of the development of public health and basic medical services, on the base of ensuring residents equality of opportunity and access to services, and supplying on-demand and respecting for their freedom choice, to realize the approximately the equalization of all urban and rural residents' health outcomes [10].

Based on the above research, the author favors of the view that to determine the connotation of the EBHS in terms of equal opportunity, equal results and equal process, and thinking that combining the needs of citizens and the supply of government can more comprehensively understand the connotation of the equalization of basic health services. Especially the view of Hong ZHAO et al that a more comprehensive and detailed overview of the equalization connotation of basic health services. Basic health services are not a simple average, but a gradual process of development, which is an equal distribution sequence in time and space. The realization of the equalization of basic public medical and health services depends on the government's public finances affordable range.

\section{Objects of the equalization of basic health services}

Scholars think that "everyone" means "every survival Chinese person", from a nationwide perspective in law, the definition of "national" is more precise than the definition of "the people" in politics and "citizens". The problem is, in a certain administrative or planning area, in addition to the household population can be identified as "enjoy" the staff, whether the floating population can also equally enjoy or not. One view is compatible, because a considerable number of floating population is worker and taxpayer, and also contributes to the economic and social development of the dependency; another view is excluded, because the current allocation of health resources is determined by the household population, and health funding is appropriated by the household population. Shou-Qi ZHOU thinks the floating population who is in a relatively fixed residence and lives more than one year should equally get access to basic health services, so as to reflect the basic health services enjoyed equal [11].

In addition, the controversy lies in whether to include foreigners living in our country and Chinese people living in overseas. Some scholars think that the equalization of public services should reflect the regional focus and humanity, in addition to covering Chinese citizens living in the country, but also covering foreigners living in china, and the Chinese citizens living abroad are excluded [12]. 
The author think that objects of the EBHS, from the perspective of Chinese national, are including both Chinese people living in China, but also foreigners who have Chinese household or live in China more than a year; from the point of view of the specific administrative area, "enjoy" the equalization objects should include both local participating in medical and have household population of the administrative area, and the floating population living more than one year in administrative regions.

\section{Chinese researches on the content of the EBHS}

Some scholars illustrated the content of the EBHS from the perspective of the content of basic health services. But other scholars made use of the specific content of basic health services to further enrich the content of the EBHS. The important steps and key links of building evaluation index system of the equalization are the division of basic health services content.

\section{Based on a static point of view of basic health services}

According to the static point of view contained in the content of basic health services, the equalization of basic health services' content, including not only the equalization of basic public health, but also the equalization of basic medical services. The basic health services were divided into basic public services and basic medical services to estimate when Yi-Yong YANG researching the EBHS provincial.

The equalization of basic public health services. Feng-Ru YAN and other scholars believe that the content of the equalization of basic public health services includes the following four aspects: the equalization of health services of urban and rural residents, the equalization of safe environment, the equalization of medical costs and the equalization of health resources [13].

Li CHEN and other scholars summarized the current the equalization of basic public health services progress, analyzed the problems in advancing the equalization and proposed recommendations on policy for the country to further improve the public health services the equalization implementation strategies [14].

Xun SUN kept the opinion that the equalization of basic public health services evaluation should cover three aspects. First is the equalization of the allocation of health resources; the following is the equalization of health services utilization; the third is the equalization of health financing [15].

Also some scholars believe that the equalization of basic public health services including the equalization of financing, accessibility, the level of protection, services utilization, and they did the empirical analysis on the level of regional economic development such as social security, fiscal expenditure structure, transfer payment system etc four aspects about the factors of the equalization of basic health services.

The equalization of basic medical services. Zhuang-Cai FU believes that it should take both supply and demand into consideration to promote the equalization of basic medical services, and he put forward the "four combinations", namely the combination of the development and reforms, the finance and system, the supply and demand, the market and society [8].

Jian-Jun WU, who used GIS accessibility indicators for objective assessments in urban and rural medical facilities distribution Lankao County of Henan Province [16]. Yuan-Fei WANG, who put forward reachability calculation method which is proposed based on GIS and geography Voronoi Polygon, studied the medical care accessibility problems in Shanghai Pudong [17].

Juan XIONG made Songzi County of Hubei Province as the researches area. She combined the reachability analysis and cluster analysis, to assess and express levels of the equalization of the medical services in different areas, and proposed some public policies [18].

\section{A dynamic perspective based on the EBHS}

The equalization of basic health services can be divided from its content, and can also be divided according to the ultimate goal. In other words, in a dynamic perspective, the EBHS can be divided into regional equalization that of urban and rural, and the equalization among different groups. Many Chinese scholars select the regional and urban-rural perspective to measure and carry out research on 
the EBHS. For example, Xin JIANG [19], Yong-Mei ZHANG [20] and others have done researches on the EBHS in urban and rural areas.

Based on the researches above, authors believe that the EBHS should include basic medical services and the equalization of basic public health the equalization. Meanwhile, the EBHS should also be achieved in different regions hat in urban and rural areas, and among different groups. Moreover, the equalization of basic health services can be measured by services capabilities the equalization, services the equalization and services results the equalization. Among which, the services capabilities of the equalization including the equalization of fund raising, personnel and institutional, and the equalization of services include basic health care and basic public health, moreover the services results in the equalization of includes indicators of health and death .etc.

\section{Research perspectives on the EBHS}

The EBHS includes the equalization of basic public health services and basic medical services. In China, researches on the EBHS mostly focused on the equalization of basic public health services. Relatively speaking, there are few researches on the equalization of basic medical services areas.

\section{The EBHS research on urban and rural perspective}

From the perspective of urban-rural differences, Yi-Yong YANG and other scholars have carried effective analysis on the equalization of basic medical services areas based on the equalization system to design of inputs and outputs [21]. Considering the decisive role of the market in accordance with the principle of resource allocation, Ling LI believes that in the aspect of production, the selection of health services employees, and the procurement of essential drugs and remuneration should fully respect the laws of the market, in accordance with the laws. Meanwhile, based on the leading role of the government public services restrictions on the market forces, she suggest returning the value of human resources back to normal, and promoting a world of survival of the fittest[22].

\section{Research perspective on the relationship between the EBHS and the financial system}

Zhong-Ming LIU and other scholars said: "Because of the inequality and the lower standards in urban and rural basic health services, and special subsidies for rural and urban; commonly, the budget is calculated repeatedly in basic medical and health institutions; funding gap of financial security policy exists; the low capital efficiency and the unreasonable immunization program funding affect basic health services the equalization effective supply in Zhejiang Province [23].

Yin ZHOU believes that financial factors are the key factors that influence the supply of basic health services, from the structure of financial expenditure on this issue, the urban-rural structure is not well-balanced, the various categories of project configuration is not rational [24].

Kai SUN believes that on the basis of the scientific definition of basic health care among all levels of government powers, it is a necessary precondition to form a government input on basic medical services system which is with clear division of labor, a reasonable share, corresponding powers and financial authority by the principle of graded burden division of basic health care between the central and local levels of government investment responsibility reasonably [25].

\section{Research perspective on the basic health services and government action}

Jun-Feng QIAO said the government plays a very important role in the equalization of basic health services in urban and rural perspective. Currently, partly due to the decentralization reform of government, there is non-equalization problem showed on this issue [26]. Ye-Wei ZHANG also believes that all levels of government, especially local government have heavy responsibility in the basic medical and health services system; they play an important role in the construction of basic rural health services system, health care resource allocation. Generally speaking, the specific duties are: to increase the budget for the supply of basic rural health care funding; reclassify financial responsibility of the main basic health care; the three basic reconstruction of rural health network; the establishment of basic health education system in rural areas; innovation in investing basic health funds among rural areas [27]. 
Overall, scholars carried researches on the EBHS from different perspectives, but in the strict sense they did not have a clear definition of the connotation of basic health services, and no researches of equalization according to it.

\section{Conclusions}

The national level of the equalization of the EBHS reflected the developed and the degree of civilization of a country. The EBHS is not a simple average, which includes two aspects, namely, the equalization of basic public health services and the equalization of basic medical services. The equalization of basic health services should include three aspects, equal opportunity and equality of results and process. At present, Chinese scholars on the equalization of basic health services, mainly the equalization of basic health services in the urban and rural, and the equalization of basic health services researches are less in the inter-regional groups. After reviewing researches on the EBHS, this paper provides a theoretical basis with the purpose to implement the EBHS of China, to achieve the equalization of basic health services ultimately.

\section{Acknowledgement}

This research was financially supported by the 2014 Natural Science Foundation of China, Project Title: Evaluation researches and Optimization Countermeasures of the equalization Lever of the Minority Regions' Basic Public Service (Project No.:71363036); Financed by 2012 Ministry of Education of Humanities and Social Science Research Project, Project Title: The Status and Countermeasures of the Basic Public Services from the Perspective of the equalization in Minority Areas (Project No.: 12YJC810007); Financed by2012 The Soft Science Project of Inner Mongolia Autonomous Region, Project Title: The Status and Policy-make of the equalization of the Basic Public Services in Inner Mongolia Autonomous Region (Project No.: 20120612); Financed by: Program for Young Talents of Science and Technology in Universities of Inner Mongolia Autonomous Region (Project NO.:NJYT-14-B01).

\section{References}

[1] Sibley L M, Weiner J P. An evaluation of access to health care services along the rural-urban continuum in Canada, BMC Health Services Researc, 2011, pp.1-31.

[2] Information on http://laws. justice. gc.ca/eng/C-6/index. html.

[3] Acheson D. Independent inquiry into inequalities in health, London: The Stationery Office Ltd, 1998

[4] Srddnivasan G. Health care and equality of opportunity, Hastings Center Report, 2007, pp.21-31.

[5] Ying-Chun LAN, Min WANG, De-Guo WANG. Ethical considerations of the equalization of basic health services,Chinese Medical Ethics,2009,pp.138-139.

[6] Xiu-Ze CHANG. The equalization of public services need institutional support urgently, Outlook, 2007, pp.48-49

[7] Ying ZHANG, Jun-Hua WANG. Research on the equalization of basic health services of safe delivery, Soft Science of Health, 2009, pp.438-440.

[8] Zhuang-Cai FU.Thinking of promoting the equalization of basic health services, Health Economics Research, 2009(2):34-35.

[9] Qiong-Lian LIU. Study on the equalization of basic public health services and its criteria, Tribune of Study, 2009, pp.54-57.

[10] Hong ZHAO, Xiao-He WANG, Xin YING, Xiao-Pei SU, Rui LI, Jian-Min GAO, Liang 
ZHANG.The research progress and pathway choice of the equalization of basic medical and health services, Chinese Journal of Health Policy, 2011,pp.29-36.

[11] Shou-Qi ZHOU. Distinction of the equalization of basic health services, Chinese Hospital Leaders ,2010,pp.50-52.

[12] Li-Mei JING, Hai-Xia XV, Bao LIU, Shan-Lian HU. A review on the theory and status quo of the quality of public health services in China, Chinese Journal of Health Policy,2009,pp.8-12.

[13] Feng-RuYAN, Zhi-Peng NIE, Kai TAN, Jian-Zhong ZHENG. Evaluation of the equalization of urban and rural residents access to health resources in ShanXi province,Chinese Journal of Public Health Management,2012,pp.17-19.

[14] Li CHEN, Lan YAO, Zhan SHU. Situation, problems and solutions of China the equalization of basic public health services,China Public Health ,2012,pp.206-209.

[15] Xun SUN, Yu-Jing ZHANG, Ming-Xin TANG, Li-Juan LIU, Xiao-Feng TANG. Definition, evaluation and measure of the equalization of basic health services, Health Soft Science, 2009, pp.424-427.

[16] Jian-Jun WU, Yun-Feng KONG, Bin LI. The Spatial accessibility analysis of rural medical facilities Based on GIS: a case study of Lankao county, Henan province,Human Geography,2008,pp.37-42.

[17] Todorava G, Durisin B. Absorptive Capacity: Valuing a Reconceptualization, Academy of Management Review, 2007, pp.74-786.

[18] Juan XIONG,Jing LUO,Jing PENG,Wen-Sheng ZHENG.The equalization analysis of medical services of county level based on accessibility,Human Geography, 2012, pp.25-29.

[19] Xin JIANG, Jia LUO. Assessments and countermeasures of the equalization of basic public services in urban and rural areas. Southwest University of Finance Press, 2012, p. 54

[20] Yong-Mei ZHANG, Fang LI. The comprehensive equalization of basic health services in urban and rural areas-based on the two national health services survey data, Journal of Guizhou Social Science), 2010, pp. 56-61.

[21] Yi-Yong YANG, Wan LIU. Our main problem and the reasons in the urban and rural social security system ,Economic Review,2007 (3):25-28.

[22] Information on http://bIog.sina.cQm,cn/s/blog 611696930100mrgo.html? ti=l

[23] Zhong-Ming LIU, Sheng-Xin XU, Yun XU, Xiang- Ming YE, Xi- Jia HU, Gu- Cong LIU. A study of the equalization of basic public health services of the financial mechanism for security system in Zhejiang province,Health Economics Research,2009, pp.5-9.

[24] Yin ZHOU. Discussion about financial investment affect public health services, Realistic, 2006, pp.185-186.

[25] Kai SUN. Research on equalization of basic health services and financial investment, Local Fiscal Studies, 2011, pp.4-8.

[26] Jun-Feng QIAO. Equity of public health service and government's responsibility: based on the reform of China's fiscal decentralization,Chinese Health Economics,2009 ,pp.5-7.

[27] Ye-Wei ZHANG.On government responsibilities in rural public health services. Journal of Zhejiang Normal University (Social Sciences), 2008, pp.61-64. 